\title{
O processo de construção de Recusa sob o olhar da dramaturgia
}

\author{
Luís Alberto de Abreu
}

\section{Resumo}

O artigo relata o processo de construção da dramaturgia do espetáculo Recusa, da Companhia de Teatro Balagan, enfocando aspectos da pesquisa do universo da cultura ameríndia e as dificuldades e soluções encontradas coletivamente na organização de uma forma que se queria distanciada do modelo clássico baseado na temporalidade e na representação.

Palavras-chave: Dramaturgia; Temporalidade; Espacialidade.

\section{Abstract}

The article relates to the construction process of the dramaturgy of the play Recusa, by Companhia de Teatro Balagan, focusing on the research aspects in the universe of the Amerindian Culture and the difficulties and solutions found collectively in the organization of a Form that wished to distance itself from the classic model based on temporality and representation.

Keywords: Dramaturgy; Temporality; Spatiality.

Recusa nasce a partir de uma pequena notícia de jornal que afetou a sensibilidade de Antonio Salvador, um dos atores. A nota trazia a informação que os dois últimos remanescentes da etnia Piripikura, índios que se mantinham arredios no interior do Mato Grosso, haviam sido descobertos. Isso só foi possível porque eles riam alto no meio da mata. Um deles estava muito doente, com o apêndice quase supurado. Foi levado ao hospital e dias depois fugiu para a mata indo ao encontro de seu parceiro. A pequena notícia trazia elementos desconcertantes que atravessaram uma pesquisa que já vinha sendo desenvolvida pelo grupo Balagan: a questão dos heróis duplos. Aos poucos, durante o processo de pesquisa, esses elementos aprofundaram-se, somaram-se a outros e se revelaram como conceitos organizadores de toda uma visão de mundo: uma visão mítica e ancestral dos indígenas que se mostrou nova e reveladora para nós. Durante a pesquisa - e entenda-se a pesquisa da Balagan como um extenso conjunto de leituras, palestras, filmes, discussões e experimentos, e, principalmente, ensaios práticos sobre os temas e os assuntos em estudo - o elemento mais evidente da notícia e o que primeiro norteou o trabalho foi a "recusa". Os dois índios recusaram contato com a pretensa "civilização branca", recu- 
saram ajuda dos "brancos". Isso, talvez, tinha menos a ver com o temor da barbárie que a civilização branca, desde o descobrimento, impôs a eles, e muito mais com a rejeição de um modo de vida e valores completamente estranhos a seu mundo. Por seu lado, a Balagan, como grupo em contínuo processo de busca e experimentação, também faz da recusa aos modelos tradicionais e hegemônicos de construção artística a base de sua pesquisa. Houve imediatas simpatia e identificação com aqueles dois indígenas. Outro tema que a notícia imediatamente impôs como objeto de estudo foi a "visão do fim". O tempo em nossa cultura ocidental-cristã é marcado por uma linha reta que vai do princípio ao fim, do gênesis ao apocalipse. O gênesis é a representação da época da grande força criativa, quando as forças da vida estão liberadas e triunfantes, no qual não existe morte e um Deus absolutamente generoso dá início à grande aventura da humanidade. No entanto, como a época de ouro da criação - a primeira ponta dessa linha reta - já aconteceu em tempos ancestrais, a nós, pobres mortais destas eras contemporâneas, apenas resta a decadência e o fim. Nossa cultura é muito mais atormentada pela ideia do apocalipse, do fim das coisas e dos tempos, do que pelo impulso de celebrar as forças iniciais da criação. Talvez por isso nos assuste e nos comova o fim de uma etnia, a visão trágica de dois índios vivendo seu próprio apocalipse. Isso é dramático aos nossos olhos e ganha um peso simbólico que vai além do desaparecimento físico dos dois indígenas. No entanto - e isso nos choca ainda mais - aparentemente, os dois piripikuras não estavam preocupados com essas nossas questões filosóficas. Eles recusavam contato e "ajuda", contavam histórias e riam, inconscientes de sua própria tragédia como nação. Inconscientes? Tragédia? Questionamo-nos se a tragédia não pertence ao nosso modo de ver o mundo. E se "inconscientes", e, principalmente, "inscientes" não somos nós em olhar para essa cultura complexa com a simplificação do nosso etnocentrismo. Como eles podem rir de seu próprio apocalipse? Talvez eles não tenham apocalipse. Talvez a cultura deles não seja essa linha reta que vai do princípio ao fim e na qual quem não viveu o grande início está irremediavelmente condenado à decadência e ao fim.

A antropologia e os parceiros antropólogos dessa empreitada de construção de Recusa foram fundamentais em nossa aventura de tentar penetrar e apreender um pouco da visão de mundo dos indígenas. E nossos questionamentos preliminares sobre as atitudes dos dois piripikuras foram ampliados. E lentamente começamos a 
caminhar em direção à visão de mundo dos ameríndios. E a perceber o quão pouco conhecemos sobre esses parceiros de cultura nacional e o quanto desprezamos seus conhecimentos. Sobre eles temos a visão de uma mancha a ser eliminada - fisicamente ou simbolicamente não importa - ou uma visão romântica como representantes de uma era edênica, de uma época de ouro já finda e que por isso devem ser preservados. Preservados por quem, cara pálida? Preservados para quê? Preservados para a compaixão e a má consciência ocidental-cristã? Isso, com razão, eles recusam. Isso aos poucos fomos apreendendo em reflexões, palestras, conversas e encontros com os antropólogos Betty Mindlin, Pedro Cesarino e Spensy Pimentel e em estudos de Viveiros de Castro e outros.

\section{Duplos e perspectivismo}

Os heróis duplos, como já foi dito, tornaram-se um conceito que penetrou forte em nossa reflexão. Ao contrário da clássica visão de mundo ocidental na qual a unidade é não só o princípio gerador das coisas, mas também o objetivo final de todo o esforço de nosso pensamento e ação, os ameríndios pensam diferente. Pares de gêmeos complementares, cada indivíduo com caráter e função diferentes, são muito presentes em seus mitos, estabelecendo uma outra forma de ver o mundo e suas relações. Enquanto na tradição ocidental o duplo tem que ser sacrificado em benefício da unidade, extirpando ou homogeneizando as diferenças, na cultura ameríndia o duplo tem de ser preservado e sua diversidade tem de ser acolhida em toda sua integridade. O duplo não se extingue em benefício da unidade, ao contrário, a unidade é formada de seu contrário. Não se entende o um sem a preservação do outro e isso se estende a toda forma de pensamento, organização social e visão de mundo. O diferente precisa existir e ser mantido, pois é complementar e fundamental para a existência do ser, da sociedade e do mundo. O diferente, o antagonista, pode ser e é causa de conflito, mas não pode de forma nenhuma ser anulado.

Mas, dentre os complexos e profundos conceitos desenvolvidos pela cultura ameríndia, o perspectivismo talvez tenha sido o mais interessante e de difícil assimilação. Nossa mentalidade trabalha com a ideia de que a vida é o traço comum que temos com todos os outros seres. O que nos diferencia e estabelece uma hierarquia entre os seres vivos é a razão e sua capacidade de estabelecer uma consciência de crenças e valores, uma cultura enfim. Um animal é inculto, presa dos instintos irracionais. Um vegetal estaciona num degrau mais abaixo por sua incapacidade de 
estabelecer comunicação e revelar intenções e vontades. Já uma pedra é inclassificável dentro desses parâmetros. Dentre os seres vivos racionais, a cultura continua a estabelecer diferenças. Valores como tecnologia, ciência, poder econômico e outros, continuam estabelecendo diferenciação e poder hierárquico entre os homens. Dentro dessa mentalidade não soa estranho o debate verificado no século XVI sobre se os indígenas tinham alma (e, portanto, eram humanos) ou se podiam ser usados como bestas de carga ou mortos em exercício de caça. Essa é a mentalidade dominante em nossa cultura: o traço comum entre os seres é serem animais, o que os diferencia é a cultura. E dentro desta se estabelece uma hierarquia. Os ameríndios pensam de maneira diferente. $O$ traço unificador entre todos os seres (animados ou inanimados) é que todos possuem cultura. Todos os seres são autônomos, dotados de reflexão e vontade, o que os diferencia é a forma com que se apresentam no mundo: formas diferentes, animadas ou não, mas todas possuidoras de humanidade. Essa mentalidade, à primeira vista, pode soar estranha ou até risível, mas possui profundas implicações na visão de mundo e no comportamento desses povos. Se todas as coisas possuem cultura, todas as coisas tem um ponto de vista, um olhar, uma perspectiva. Tanto eu olho para a pedra como a pedra me olha. Tanto eu penso sobre o animal como o animal pensa sobre mim e pode estabelecer conclusões não muito acertadas. Por isso tanto eu como o animal necessitamos olhar com a perspectiva do outro. $E$ as relações entre os seres e as coisas se dão dentro desse perspectivismo. Para conhecer a coisa eu preciso olhar com a perspectiva da coisa, seja a coisa uma pedra ou uma onça. Só assim se estabelece uma relação equilibrada e um conhecimento profundo entre todos os seres e coisas, pois o que diferencia cada um deles é a forma como a cultura de cada um se expressa. Uma pedra ou uma árvore é apenas uma forma diferente de humanidade. Por isso o vento pode cantar ou decidir, por si, ir soprar em outro lugar perto de seus parentes; macaco já foi gente como nós até o dia que resolveu, por vontade própria, seguir o destino de macaco; uma pedra pode resolver desaparecer ou aparecer de acordo com sua própria vontade e uma árvore pode resolver guardar dentro de si um índio ou uma entidade. O mundo, para o indígena, ainda não perdeu a instabilidade e o mistério; e é dentro do mistério que tudo pode acontecer. É um mundo às avessas do mundo de nossas crenças, este que nos assusta e que acreditamos que marcha inexoravelmente para o fim, para o apocalipse. Dentro do mistério do mundo tudo pode acontecer, inclusive a esperança do não-fim, da recriação do mundo, da 
renovação da vida, da volta dos mortos etc. Isso os indígenas creem e vivem. Nosso mundo, ao contrário, é estável, não existe espaço não preenchido, não existe vácuo. Todo espaço para nós - como era para o pensamento grego clássico - é lugar das coisas. E as coisas estão separadas, classificadas, completamente conhecidas. Céu, inferno, deuses, sentimentos, coisas, animais, humanos, tempo, estão todos separados e em seus lugares. E, se não estiverem, é bom que estejam, assim grita nossa razão. Para a razão indígena todos os espaços, tempos e coisas são cambiáveis. O mundo e o tempo são espaços transitáveis por todos. O sono e a vigília, o vivo e o morto, o passado e o futuro transitam livremente no presente e qualquer coisa é elemento de uma mesma realidade dinâmica, múltipla e aberta a novas configurações.

Essa multiplicidade de humanidades presentes em todas as coisas afasta 0 trágico, pois o fim absoluto é inexistente. O que existe são transmutações. Talvez seja essa a razão do riso tão presente na cultura e no comportamento de nossos indígenas. Nenhuma perda é absoluta e a vida, de uma forma ou de outra, numa enorme corrente de mutações, terá sempre o mesmo sabor, será sempre imprevista e surpreendente.

Bem, isso tudo foi escrito e pensado agora, como síntese precária e repleta de lacunas do processo vivido nesse projeto. É um mapa a posteriori, de contornos mais ou menos nítidos e suficientemente lógicos. Mas no território do processo a realidade foi outra. A aproximação com o universo da cultura indígena foi lenta, intrigante e entusiasmada, mas também dificultosa. Não queríamos escrever "sobre" os piripikuras. Seria relativamente fácil estabelecer a pesquisa necessária, extrair dela alguns conceitos e construir uma dramaturgia ao gosto e ao modo dos padrões teatrais conhecidos. Mas não era isso que queríamos. Talvez quiséssemos trocar, fazer da construção desse trabalho uma experiência de escambo, um espaço onde pudéssemos aprender que coisas nos atraíam naqueles dois indígenas e que não conhecíamos. Como afirmou uma vez Maria Thaís: "só topei a imagem inicial (dos dois indígenas) porque me reconhecia, como artista, nela. Uma recusa artística, uma recusa que precisava ter coragem de fazer." Este foi um nível inicial de identificação com o material, outros vieram depois. Mas foi aí que começaram as dificuldades. Não é fácil abandonar o que se sabe, o conforto das soluções já testadas e sabidamente eficientes, mas se quiséssemos, de fato, penetrar naquela imagem inicial e realizar a experiência da troca com aquele universo cultural era necessário começar a aprender com aquela simples notícia de jornal. É claro que conhecíamos alguns mitos, lendas e conceitos da cultura indígena, 
mas estávamos muito distantes de sua visão de mundo e de sua forma de expressá-lo. Ao final dos estudos, discussões e improvisações, a dramaturgia propôs um "canovaccio" na tentativa de organizar o material cênico resultante até aquele momento. Isto foi recusado de pronto. Mas dizer o que não se queria era/é, evidentemente, mais fácil do que acertar o rumo de uma busca obscura para nós mesmos.

Em fevereiro de 2011 o grupo fez uma viagem à aldeia-Paiter-Suruí, em Rondônia. Foi um divisor de águas porque trouxe elementos muito concretos. Viver no meio dos Paiter-Suruí, no meio de suas narrativas, no canto, nas festas, observar tudo isso materialmente mudou muita coisa. Tínhamos já algum material cênico levantado, mas a questão era que forma dar a ele tanto na performance, quanto na escrita. A temporada com os Paiter-Suruí trouxe elementos valiosos para a composição da performance narrativa. Foi elaborado e aprovado um novo "canovaccio" que expressava melhor os caminhos das inquietações do grupo. No entanto, numa leitura pública, ele se revelou um tanto limitador do universo que o projeto apontava e que a recente experiência em Rondônia estimulara.

\section{Rapsódia, interlíngua, espacialidade}

Para se afastar da organização clássica, a dramaturgia propõe uma estrutura rapsódica que se define como uma composição de assuntos heterogêneos e de várias origens. Àquela altura, a rapsódia, que sistematizava cenas escritas pela dramaturgia e material proposto pelos atores, parecia ser a melhor organização. Embora trabalhássemos o mesmo canovaccio, a ideia era não tentar unificar o material variado que tínhamos dentro de uma única ideia de desenvolvimento, dentro de uma única lógica de dramaturgia. Mas a própria estrutura rapsódica mostrou-se insuficiente. Macunaíma é uma rapsódia de lendas afro-indígenas unificadas por seu protagonista. Mas a ideia do protagonismo nos deixava muito próximos do conceito clássico que tentávamos escapar. Não queríamos transformar os piripikuras em personagens, em articuladores de um discurso individual, pois, afinal, não fomos em busca daqueles personagens, fomos em busca daquela cultura que fazia aqueles dois indivíduos exercerem seu direito à recusa. A rapsódia tinha que transformar-se em outra coisa, mas esse momento ainda não havia chegado.

O ponto de mudança começou quando o material colhido da viagem começou a se integrar às improvisações. Anteriormente, os atores já haviam experimentado utilizar o tupi-guarani nos diálogos e haviam utilizado outros dialetos indígenas nas canções 
e outras contribuições musicais de Marlui Miranda, responsável pela preparação musical do espetáculo. E veio dela a ideia da síntese que ela própria chamou de interlíngua, um hibridismo de português, tupi e termos de outros idiomas, apropriada pelos atores. Por outro lado, o canto foi se desdobrando, invadindo naturalmente o espaço da escrita narrativa e se desdobrando em signo tão fundamental quanto o texto e o gesto; afinal, para os indígenas, a fala, o canto e o gesto são elementos compositores de suas narrativas. Isso começa a alterar significativamente as narrativas propostas pela dramaturgia, a buscar uma essência textual baseada na sonoridade e nas imagens e eliminando conectivos e outros empecilhos gramaticais à livre expressão da ação. Há aqui, como aponta Maria Thaís, um deslocamento do problema: “É a construção da língua que expressa uma mentalidade e não a representação, a imitação do "modo de falar" - imitação do sotaque, da voz etc." Já não precisávamos da imitação para remeter ao universo dos piripikuras, a interlíngua apropriada pelos atores se encarregava de, ficcionalmente, dar a credibilidade e presença da cultura indígena.

Ainda há algo a se falar com relação à música, um elemento marcante e presente desde o início do processo. Tínhamos a intuição que ela seria matéria importante na construção da obra, mas não sabíamos exatamente como. Para mim, a música sempre tem uma relação problemática com a dramaturgia em razão de sua força, muitas vezes, avassaladora. Não é coisa fácil estabelecer uma harmonia entre elementos musicais, textuais e de ação cênica. Em geral, a relação do teatro com a música se dá em extremos: ou a música se torna elemento subalterno, funcionando como fundo ilustrativo da cena, elemento reforçador ou criador das intensidades, tensões, atmosferas, ou torna-se elemento preponderante como na ópera e no musical, reconfigurando a cena e a dramaturgia. Este era um desafio a ser enfrentado e, de antemão, excluímos os dois extremos. A música é um elemento forte e natural na cultura indígena. Nela, fala e canto se mesclam, muitas vezes, sem distinção. O caminho apontado era esse e, no processo em que estávamos envolvidos, a dramaturgia não devia responder diretamente a essa questão, ou seja, confiávamos que o processo de trabalho com todos os criadores fosse nos dar respostas. Foi o que aconteceu. O fato de não estabelecermos uma forma a priori, permitiu que o material cênico (e consideramos material cênico toda e qualquer produção concreta de qualquer área de criação) amadurecesse e apontasse seu lugar na geometria cênica. De fato, respeitamos todo o material produzido, quer no aproveitamento, quer no descarte. Foi esse respeito ao material 
produzido e sua importância estética, sentido ético e potencial de comunicação, que nos orientou.

A pesquisa avançou também na área da cenografia com o estudo de cor, volumes e espaço aprofundados pelo cenógrafo Márcio Medina e que trouxeram novos elementos para a estruturação do trabalho.

Avançamos muito nessa altura, mas não o suficiente. Neste momento a direção de Maria Thaís teve um papel decisivo. Não que não o tivesse em outros momentos, mas a partir desse ponto do processo sua atuação foi fundamental. Mais do que diretora do espetáculo, ela foi diretora do processo, pontuando, refletindo, questionando, retomando certos conceitos e desejos que tínhamos no princípio para que o envolvimento na construção das cenas não nos levasse a perdê-los. No começo do processo tínhamos intenções de ir além dos elementos do drama e da representação e Thaís pontuava no sentido relembrar e reavivar essas intenções primeiras. É nessa altura que o conceito de espacialidade que a diretora trouxera deste o início do processo, começou a ganhar corpo e necessariamente se impôs como conceito articulador de todo o trabalho.

O teatro se dá é no espaço da relação entre os atores e o público. $\mathrm{E}$, nesse sentido, ele prescinde de história, do drama e de outros elementos que, na verdade, podem constituí-lo, mas que não podem ser considerados essenciais. Em outras palavras, o conceito de espacialidade que ali começávamos a buscar e a aprofundar criava uma questão para a dramaturgia. Em outras palavras, pretendia-se que a performance dos atores, o ato teatral em si, tivesse preponderância sobre a articulação da história. Em outras palavras ainda, o conceito de espacialidade propunha o abandono de um milenar paradigma da dramaturgia: a temporalidade.

Todas as coisas concretas acontecem num tempo e num espaço determinados, ponto. Tradicionalmente a dramaturgia ocidental se configurou com uma forte inflexão no tempo, entendido, em nossa mentalidade, como desenvolvido entre um ponto inicial e um ponto final, de que falávamos no começo desse artigo. Na Poética, Aristóteles chama atenção para a necessidade de construir o drama como princípio, meio e fim. $E$, inclusive, define cada um desses termos. Num drama as cenas e ações se dão por consecução coerente e necessária, do princípio até o final. O que se pretendia, agora, no processo, era esmaecer a noção de tempo e valorizar a noção de espaço de tal forma que o fenômeno teatral se desse apenas no tempo presente da encenação 
e na performance dos atores. A proposta que o conceito de espacialidade trazia era eliminar qualquer relação causal de uma cena para outra, qualquer vestígio de hierarquia entre as cenas, qualquer ordenação lógica a priori. A coerência seria determinada pela própria construção do espetáculo. E mais: eliminar qualquer personagem que pudesse ser o articulador do discurso narrativo. A partir desse ponto, não eram mais os piripikuras que narravam, eles não eram mais personagens, eram figuras históricas às quais o espetáculo fazia referência, mas nem sequer eram seus personagens narradores. Os narradores eram outros: eram os atores Antonio Salvador e Eduardo Okamoto, que davam corpo a diferentes vozes narrativas, de diferentes culturas. $\mathrm{O}$ conceito de rapsódia começa a se desmanchar no ar.

Teoricamente é compreensível, mas na prática como é que se abandona a noção de história, de consecução organizada de cenas que conduzam a determinado sentido? Como é que se abandona o fio condutor, que dá sentido ao todo de uma peça, como sempre aprendemos e praticamos? Dentro da estrutura do drama trabalha-se com uma série de hierarquias: do enredo em relação ao desenredo, do protagonista em relação aos outros personagens, de uma cena em relação à outra e da cena catártica em relação a todas as outras. Mesmo quando nos afastamos dessa abordagem clássica, a série de hierarquias permanece de um jeito ou de outro. É difícil abrir mão da segurança mínima de que é a arte sequencial, do conforto criativo de alinhavar cena sobre cena para que conduzam a determinado fim. Há muitos séculos nos acostumamos a esse artesanato dramatúrgico, há muitos séculos o público se acostumou a essa forma e suas expectativas concorrem para ela. Felizmente, na Balagan, tanto os riscos quanto as responsabilidades são encaradas coletivamente. $E$ isso facilitou em muito o trabalho da dramaturgia. Lentamente foi-se abrindo mão de cada coisa que pudesse ser/representar ligação temporal ou hierarquia entre uma narrativa e outra. O objetivo era arrojado: narrativas autônomas que tivessem sua força vinculada à própria experiência que traziam na performance dos atores e que prescindissem de uma unificação que lhes dessem sentido. O sentido geral seria dado por cada uma das unidades. Melhor dizendo, o sentido seria conferido pela própria encenação. O pensamento da peça, o sentido do espetáculo não seria um dado a priori do dramaturgo, mas resultado do pensamento e da ação de todo coletivo criador. Incluído nesse coletivo criador o próprio público que estabeleceria as ligações e extrairia dali um sentido. Queríamos um conjunto de narrativas/cenas, uma organização cênica que não tivesse 
por base a noção de tempo que nossa cultura está acostumada a operar: principio e fim, enredo e desenredo. Queríamos que o único tempo fosse o tempo da ação teatral, do aqui, do agora, da performance dos dois atores frente ao seu público. Caminhamos para isso porque pressentimos que isso fosse caminhar em direção à cultura daqueles dois indígenas isolados que foram descobertos conversando e rindo no meio da mata. Não sei avaliar a que lugar chegamos, mas caminhamos muito. 